\title{
Article \\ DES Based Efficient Extraction Method for Bioactive Coumarins from Angelica dahurica (Hoffm.) Benth. E Hook.f. ex Franch. E Sav.
}

\author{
Ting Wang and Qian $\mathrm{Li}$ *(iD) \\ Gansu Provincial Key Laboratory of Aridland Crop Science, College of Agronomy, Gansu Agricultural University, \\ Lanzhou 730070, China; wangting2021echo@163.com \\ * Correspondence: liqian1984@gsau.edu.cn
}

check for updates

Citation: Wang, T.; Li, Q. DES Based Efficient Extraction Method for Bioactive Coumarins from Angelica dahurica (Hoffm.) Benth. E Hook.f. ex Franch. E Sav. Separations 2022, 9, 5. https://doi.org/10.3390/separations 9010005

Academic Editor: Ki Hyun Kim

Received: 30 November 2021

Accepted: 21 December 2021

Published: 23 December 2021

Publisher's Note: MDPI stays neutral with regard to jurisdictional claims in published maps and institutional affiliations.

Copyright: () 2021 by the authors Licensee MDPI, Basel, Switzerland. This article is an open access article distributed under the terms and conditions of the Creative Commons Attribution (CC BY) license (https:// creativecommons.org/licenses/by/ $4.0 /)$.

\begin{abstract}
In this study, a simple and environmentally friendly method was developed for the extraction of seven active coumarins from Angelica dahurica (Hoffm.) Benth. E Hook.f. ex Franch. E Sav. (A. dahurica) based on deep eutectic solvents (DESs). Among the 16 kinds of DES based on choline chloride, the DES system with the molar ratio of choline chloride, citric acid, and water as 1:1:2 had the best extraction effect. Ultrasonic-assisted response surface methodology (RSM) was used to investigate the optimal extraction scheme. The results showed that the optimal extraction conditions were a liquid-solid ratio of 10:1 (mL/g), an extraction time of $50 \mathrm{~min}$, an extraction temperature of $59.85{ }^{\circ} \mathrm{C}$, and a moisture content of $49.28 \%$. Under these conditions, the extraction yield reached $1.18 \%$. In addition, scanning electron microscopy (SEM) was used to observe the degree of powder fragmentation before and after extraction with different solvents. The cells of A dahurica medicinal materials obtained by DES ultrasonic-assisted treatment were the most seriously broken, indicating that DES had the highest efficiency in the treatment of $A$. dahurica. The 1,1-diphenyl-2-picrylhydrazyl (DPPH) DPPH radical scavenging model was used to evaluate the biological activity of DES extract. The results showed that DES extract had better scavenging ability of DPPH free radical. Therefore, DES is a green solvent suitable for extracting coumarin compounds of $A$. dahurica, with great potential to replace organic solvents.
\end{abstract}

Keywords: deep eutectic solvents; Angelicae dahuricae; coumarins; response surface methodology

\section{Introduction}

Angelica dahurica (Hoffm.) Benth. E Hook.f. ex Franch. E Sav. (A. dahuricae) is the dry root belonging to umbelliferaceae. A. dahuricae has been frequently used as a food additive and a folk medicinal herb in Asian countries [1]. A. dahuricae has a wide range of pharmacological activities, including analgesia, anti-inflammatory, antibacterial, vascular dilation, anti-cancer, and central excitatory properties, and so on [2]. It has been used as an anodyne, and is very effective at relieving neuralgic pain [3]. A. dahuricae is known to contain a large number of compounds, including volatile oil, coumarins, and glycosides. Among these compounds, coumarins are generally considered the major components; so far, more than 20 kinds of coumarins have been isolated from this crude drug, such as oxypeucedanin, imperatorin, cnidilin, isoimperatorin, xanthotoxol, byakangelicin, bergapten, etc. [4]. Therefore, the efficient extraction of coumarins is important and desirable.

As known to us, a major disadvantage of conventional methods such as impregnation, percolation, and soxhlet extraction using alcohol or other common organic solvents is the use of a large number of flammable, non-degradable, or toxic organic solvents in the extraction process. In order to solve this problem, a new green natural deep eutectic solvents (NADESs) has been studied [5]. Compared to traditional organic solvents, NADES is a promising alternative to traditional organic solvents because of its green, non-toxic, biodegradable, and recyclable properties [6]. 
At present, DESs are widely used in science to extract the following types of biologicallyactive substances (BASs): flavonoids, alkaloids, anthocyanins, flavors, saponins, etc. [7]. DESs are mostly composed of primary metabolites such as sugars, sugar alcohols, organic acids, amino acids, and amines and additionally often contain water in certain molar ratios [8]. Compared with traditional extraction solvents, DESs could improve the extraction rate of products, which is an effective method to extract bioactive products [9]. Owing to these unique properties, DESs have been widely used in catalysis, organic synthesis, and analytical chemistry $[10,11]$. DESs have been widely used in liquid-liquid extraction, solid-phase microextraction, and other fields [12]. Recently, several studies used DESs for the extraction and separation of different types of bioactive compounds, such as phenolic acids, flavonoids, and alkaloids from various plant materials [13]. In general, the extraction capacity of DESs for biologically active natural products is related to their physicochemical properties, including H-bond interactions, polarity, $\mathrm{pH}$, and viscosity. The polarity of DESs is an important factor affecting the extraction efficiency. Due to the high polarity of synthesized DESs, they have been used for the extraction of polar natural compounds like alkaloids, anthocyanins, polysaccharides, and glycosides. In general, as for natural compounds with low polarity, such as anthraquinones, their extraction rate is low [6,14]. In addition, the solid-liquid ratio of the sample to the DES, the extraction time, and even the molecular weight of the DES may affect the extraction effect. A high-efficiency and green extraction approach by DESs prepared by inexpensive and natural components was successfully developed for the extraction of coumarins in Cortex Fraxini by Wang et al. [15].

Ultrasonic-assisted extraction (UAE) UAE can significantly improve the efficiency of the classical extraction process, and the combination of UAE with NADESs can also be effective [16]. Compared with the conventional method using $96 \%$ ethanol as solvent, the NADES-UAE method had higher extraction efficiency for trans-cinnamaldehyde and coumarin from C. burmanni by Widya Dwi ARYATI $[17,18]$. Chen et al. established a liquid chromatography-tandem mass spectrometry (LC-MS /MS) method for simultaneous quantification of nine furanocoumarins, which could separate nine furanocoumarins within $6 \mathrm{~min}$ [19]. Pfeifer et al. detected coumarin in A. dahurica roots by supercritical fluid chromatography [20]. However, as known to us, the method of extracting bioactive compound coumarins by DESs is still limited, and the efficiency of extracting coumarin from A. dahuricae is not clear.

In this study, a series of DESs based on choline chloride was developed to evaluate the extraction effect on coumarin of A. dahurica. A Box-Behnken design (BBD) and the response surface method (RSM) were used to optimize the extraction conditions of DESs. Scanning electron microscopy (SEM) was used to study the degree of crushing of medicinal powder by ultrasonic-assisted DES and conventional extraction. Finally, the scavenging effect of DES extract on DPPH free radical was studied.

\section{Experimental}

\subsection{Materials and Reagents}

A. dahurica was purchased from Suining City, Qing Mountain sulphur free food store (Sichuan, China). An appropriate amount of medicinal materials was taken and baked in an oven at $60^{\circ} \mathrm{C}$ for $24 \mathrm{~h}$. Then, they were crushed through a 40-mesh sieve and the coarse powder of A. dahurica root was obtained, which was put into a zipper bag for use.

All the chemicals for the preparation of the DES and coumarins were purchased from companies in several Chinese cities mentioned later. Analytical reagents such as choline chloride, sucrose, xylitol, citric acid, glucose, ethylene glycol, 1,2-propanediol, 1,4butanediol, 1,3-butanediol, glycerol, fructose, and urea were purchased from Sinopharm Chemical Reagent Co., Ltd. (Shanghai, China); malic acid was purchased from Shanghai Sanpu Chemical Co., Ltd. (Shanghai, China); acetic acid was purchased from Tianjin Beichenfang Reagent., Ltd. (Tianjin, China) and lactic acid was purchased from Yantai Shuangshuang Chemical Co., Ltd. (Yantai, China). All the above reagents are analytically pure. 
Oxypeucedanin (lot: Y29S9S65152 $\geq 98 \%$ ), isoimperatorin (lot: $18062202 \geq 98 \%$ ), bergapten (lot: $17120501 \geq 98 \%$ ), psoralen (lot: $19101703 \geq 98 \%$ ), imperatorin (lot: $1805150 \geq 98 \%$ ), and xanthotoxol (lot: $19111602 \geq 99 \%$ ) were purchased from Chengdu Pufeide Biological Technology Co., Ltd. (Sichuan, China)Byakangelicin (lot: B-005-180921 $\geq 98 \%$ ) was purchased from Chengdu Ruifensi Biological Technology Co., Ltd. (Sichuan, China) The deionized water used in this study was obtained from a Milli-Q water purification system (Bedford, NY, USA). All other reagents and chemicals used were of analytical grade. The chemical structures of coumarins used in this study are shown in Figure 1.<smiles>O=c1ccc2cc3ccoc3c(O)c2o1</smiles>

xanthotoxol<smiles>CC1(C)OC1COc1cc(=O)oc2cc3occc3cc12</smiles>

oxypeucedanin<smiles>O=c1ccc2cc3ccoc3cc2o1</smiles>

psoralen<smiles>COc1c2ccoc2c(OC[C@H](O)C(C)(C)O)c2oc(=O)ccc12</smiles>

byakangelicin<smiles>COc1c2ccoc2cc2oc(=O)ccc12</smiles>

bergapten<smiles>CC(C)=CCOc1c2ccoc2cc2oc(=O)ccc12</smiles>

isoimperatorin

Figure 1. Chemical structures of xanthotoxol, psoralen, byakangelicin, bergapten, oxypeucedanin, imperatorin, and isoimperatorin.

\subsection{Preparation of DESs}

The direct synthesis method of DESs is easy to operate and has few equipment requirements. The mixture with a certain molar ratio was put into a small beaker of $100 \mathrm{~mL}$ and stirred in an oil bath at a certain temperature $\left(80-90^{\circ} \mathrm{C}\right)$ until a uniform and stable transparent liquid was formed (generally 120-180 min). Because some components have high viscosity and a high melting point, it was difficult to obtain an ideal solvent by the direct heating synthesis method. A certain proportion of water should be added before heating to reduce the viscosity. Five kinds of three-phase DESs and 11 kinds of two-phase DESs were prepared by the above method, which are shown in the following Table 1.

Table 1. List of DESs synthesized in this study.

\begin{tabular}{ccccc}
\hline No. & $\begin{array}{c}\text { Hydrogen Bond } \\
\text { Acceptors (HBAs) }\end{array}$ & $\begin{array}{c}\text { Hydrogen Bond } \\
\text { Donors (HBDs) }\end{array}$ & $\begin{array}{c}\text { HBA/HBD } \\
\text { (Water) Ratio }\end{array}$ & $\begin{array}{c}\text { Appearance at } \\
\text { RoomTemperature }\end{array}$ \\
\hline 1 & Choline chloride & Sucrose & $1: 1:(2)$ & Transparent liquid \\
2 & Choline chloride & Xylitol & $1: 1:(1)$ & Transparent liquid \\
3 & Choline chloride & Citric acid & $1: 1:(2)$ & Transparent liquid \\
4 & Choline chloride & D-Glucose & $1: 1:(2)$ & Transparent liquid \\
5 & Choline chloride & DL-Malic acid & $1: 1:(2)$ & Transparent yellow liquid \\
6 & Choline chloride & Acetic acid & $1: 2$ & Transparent liquid \\
7 & Choline chloride & Lactic acid & $1: 3$ & Transparent liquid \\
8 & Choline chloride & Lactic acid & $1: 2$ & Transparent liquid \\
9 & Choline chloride & Ethylene glycol & $1: 2$ & Transparent liquid \\
10 & Choline chloride & 1,2-Propanediol & $1: 2$ & Transparent liquid \\
11 & Choline chloride & 1,4-Butanediol & $1: 2$ & Viscous liquid \\
\hline
\end{tabular}


Table 1. Cont.

\begin{tabular}{ccccc}
\hline No. & $\begin{array}{c}\text { Hydrogen Bond } \\
\text { Acceptors (HBAs) }\end{array}$ & $\begin{array}{c}\text { Hydrogen Bond } \\
\text { Donors (HBDs) }\end{array}$ & $\begin{array}{c}\text { HBA/HBD } \\
\text { (Water) Ratio }\end{array}$ & $\begin{array}{c}\text { Appearance at } \\
\text { RoomTemperature }\end{array}$ \\
\hline 12 & Choline chloride & 1,3-Butanediol & $1: 2$ & Viscous liquid \\
13 & Choline chloride & Glycerol & $1: 2$ & Transparent liquid \\
14 & Choline chloride & Glycerol & $1: 3$ & Transparent liquid \\
15 & Choline chloride & Fructose & $1: 2$ & Transparent liquid \\
16 & Choline chloride & Urea & $1: 2$ & Transparent liquid \\
\hline
\end{tabular}

\subsection{Experimental Design}

\subsubsection{Preparation of Standard Solution}

A certain amount of standard was precisely weighed, placed in a $10 \mathrm{~mL}$ volumetric flask, and then filled with methanol to the scale line to obtain 7 standard solutions of varying concentrations. Then, $1 \mathrm{~mL}$ of each standard solution was precisely sucked and added to the same volumetric flask to obtain a mixed standard solution. After filtration with $0.45 \mu \mathrm{m}$ microporous membrane, the mixed standard solution was injected into highperformance liquid chromatography (HPLC) at different volumes $(4,8,10,12,16,20 \mu \mathrm{L})$, and the peak area was recorded for each.

\subsubsection{Preparation of Sample Solution}

In the initial screening, $1 \mathrm{~g} A$. dahurica herb powder was accurately weighted and added to a $150 \mathrm{~mL}$ conical flask with a certain proportion of DES solvent. After vortexing, the mixture was put into an ultrasonic bath at $60^{\circ} \mathrm{C}, 300 \mathrm{~W}$ power, and $50 \mathrm{~Hz}$ for $60 \mathrm{~min}$, then the solution was collected and centrifuged at $6000 \mathrm{RPM}$ for $15 \mathrm{~min}$. A total of $1 \mathrm{~mL}$ of the preparation solution was added to a $5 \mathrm{~mL}$ volumetric flask and the volume was fixed with methanol to the scale line. Then it was filtered through a $0.45 \mu \mathrm{m}$ filter and quantified by HPLC analysis. Each experiment was performed three times.

\subsubsection{Traditional Extraction Method Comparison}

Compared with traditional extraction methods, $75 \%$ ethanol and methanol were used for an ultrasonic bath $\left(300 \mathrm{~W}, 50 \mathrm{~Hz}, 60^{\circ} \mathrm{C}, 60 \mathrm{~min}\right)$. After filtration with a $0.45 \mu \mathrm{m}$ microporous membrane, $10 \mu \mathrm{L}$ of filtrate were injected into HPLC for analysis, and the yield of total coumarins was calculated.

\subsection{Single-Factor Experimental Analysis of Extraction of Coumarins from A. dahurica \\ 2.4.1. Effect of Liquid-Solid Ratio}

As shown in Figure 2, the extraction rates of different liquid-solid ratios (10, 20, 30, 40, $50 \mathrm{~mL} / \mathrm{g}$ ) were investigated under ultrasonic bath conditions $\left(300 \mathrm{~W}, 50 \mathrm{~Hz}, 60 \mathrm{~min}, 60^{\circ} \mathrm{C}\right)$ and $30 \%$ DES moisture content. When the liquid-solid ratio was 20:1, the extraction rate reached the highest value of $2.06 \%$. When the liquid-solid ration continued to increase, the extraction rate showed a decreasing trend, because the increase in the liquid-solid ratio can make the system have higher solubility and promote the breakdown of cell walls, aiming to increase the overflow ratio of the content. However, when the solubility is large enough, there will be a saturation phenomenon, which would lead to some components not being dissolved, resulting in waste of extraction solvent and complexity of the extraction process, thus affecting the extraction effect. 


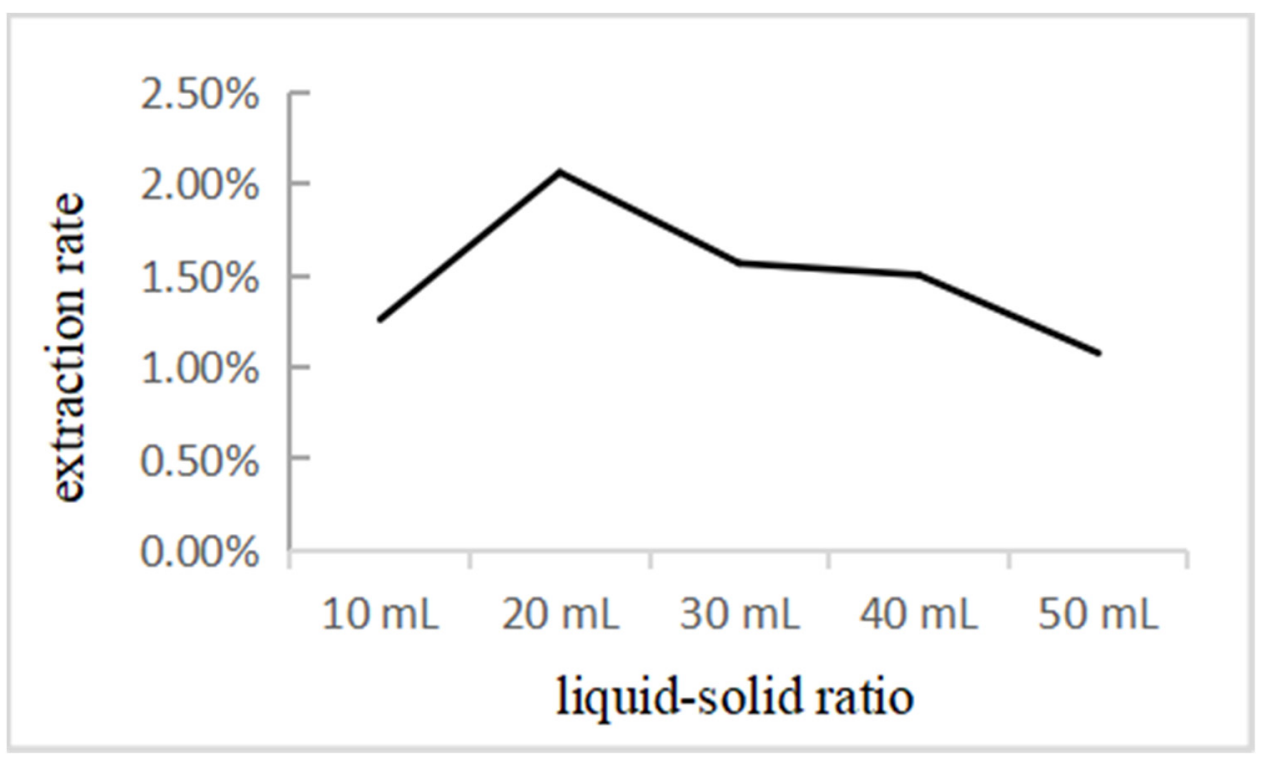

Figure 2. Effect of liquid-solid ratio on the extraction yield of coumarins.

\subsubsection{Effect of Extraction Temperature}

Extraction rates at different temperatures $\left(40,50,60,70,80^{\circ} \mathrm{C}\right)$ were investigated under ultrasonic bath conditions $(300 \mathrm{~W}, 50 \mathrm{~Hz}, 60 \mathrm{~min})$, a liquid-solid ratio of 10:1, and $30 \%$ DES moisture content. Extraction temperature is the key factor affecting extraction rate. The target compound is adsorbed on the sample matrix by physical adsorption and chemical interaction, which would be reduced by high temperatures, thereby increasing the leaching of the target compound in the extraction solvent. In addition, a high extraction temperature can greatly reduce the viscosity of the extraction solvent, increase the diffusion of the extraction solvent, and accelerate the mass transfer of the target compound. Figure 3 shows that the extraction temperature of $50{ }^{\circ} \mathrm{C}$ provided a higher extraction rate than the other test extraction temperatures. Although a higher extraction temperature may improve extraction yield, it may not be able to avoid the thermal degradation of active ingredients at high temperatures [21]. Therefore, the extraction temperature of $50{ }^{\circ} \mathrm{C}$ was selected as the optimal extraction temperature in this study.

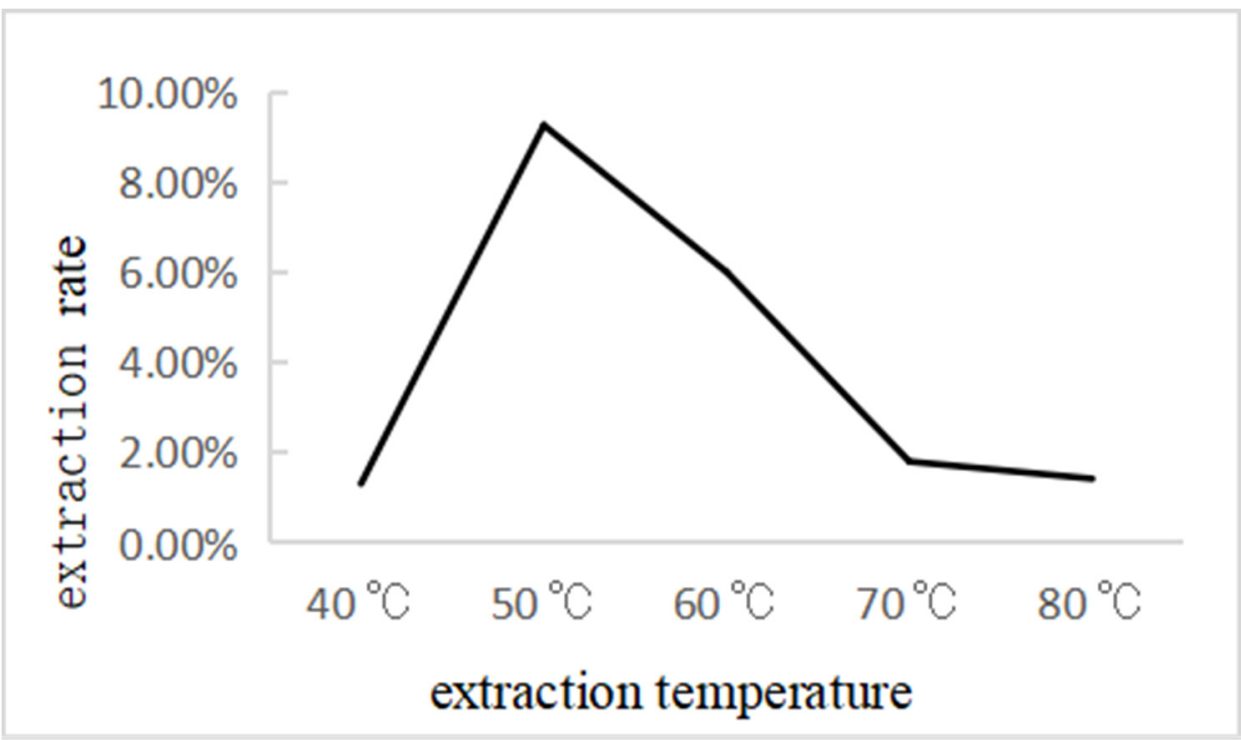

Figure 3. Effect of extraction temperature on the extraction yield of coumarins. 


\subsubsection{Effect of Extraction Time}

To some extent, the extraction rate is always proportional to the extraction time [22]. As shown in Figure 4, different extraction times (30, 40, 50, $60 \mathrm{~min})$ were investigated under the conditions of an ultrasonic bath $\left(300 \mathrm{~W}, 50 \mathrm{~Hz}, 60^{\circ} \mathrm{C}\right)$, a liquid-solid ratio of 10:1, and a DES moisture content of $30 \%$. The extraction rate showed an upward trend at $30-40 \mathrm{~min}$, and a downward trend at $40-60 \mathrm{~min}$. This may have been because the longer the time, the greater the energy generated by ultrasonic waves, forming a strong cavitation effect in the solution, which will cause more damage to the cell wall of medicinal materials, which means the extraction rate is also greater $[23,24]$. However, with the extension of the ultrasonic action time, the amount of extraction decreases, which may be because when the sample is under long-term ultrasonic action and a high temperature of $60^{\circ} \mathrm{C}$, the system is affected by ultrasonic radiation and thermal effect, which may produce double degradation. Therefore, $40 \mathrm{~min}$ was selected as the optimal extraction time at $60{ }^{\circ} \mathrm{C}$. The extraction time was 20 min less than that of the traditional extraction method.

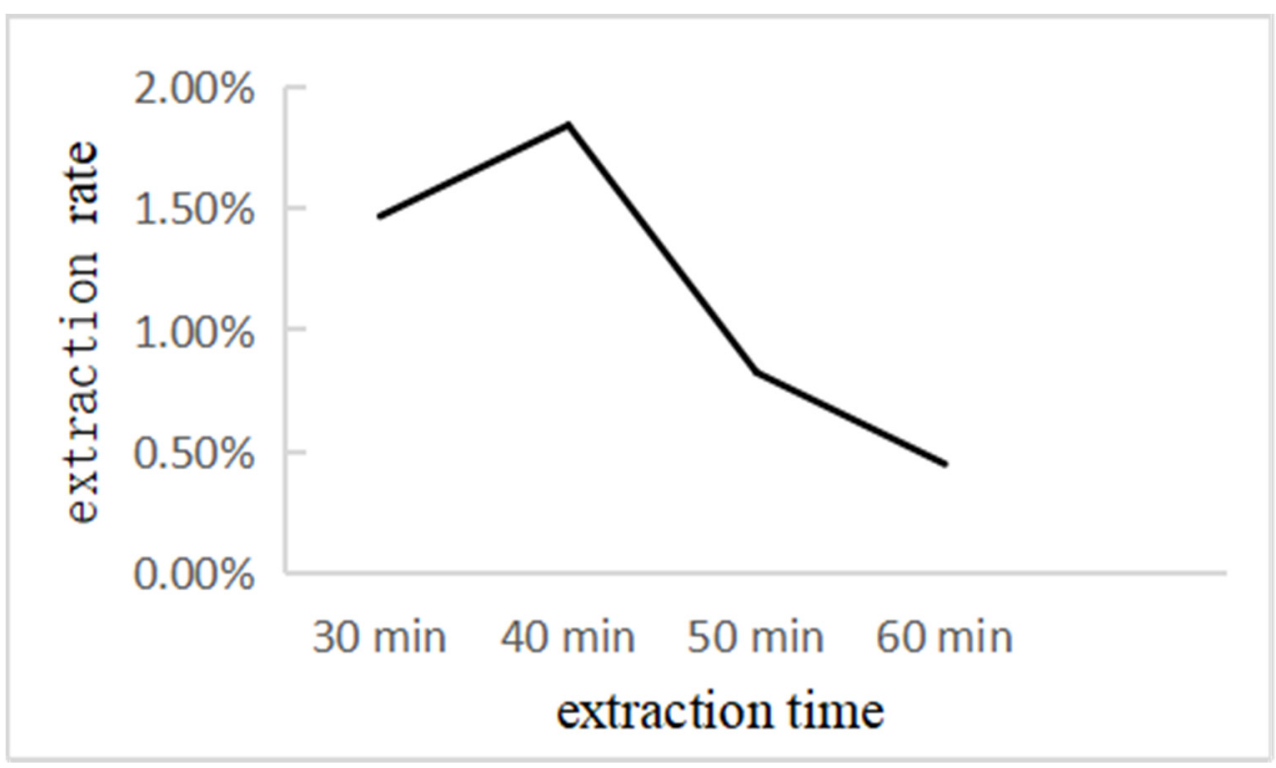

Figure 4. Effect of extraction time on the extraction yield of coumarins.

\subsubsection{Effect of DES Moisture Content}

There are extensive hydrogen bond networks among DES components, resulting in high viscosity and weak mobility. Its viscosity and fluidity must be altered to obtain good permeability of the pores in the sample matrix and to facilitate mass transfer from the plant matrix to the solution. Adding water to DES can significantly reduce the viscosity and improve the extraction rate. In addition, the DES-water mixture is more alkaline and has a lower cost of extracting the target compound than the normal DES solvent [10]. Therefore, the extraction rate appears to be strongly dependent on the water content of the DES solution. As can be seen from Figure 5, different DES moisture counts were investigated under the conditions of an ultrasonic bath $\left(300 \mathrm{~W}, 50 \mathrm{~Hz}, 60 \mathrm{~min}, 60^{\circ} \mathrm{C}\right)$, and a liquid-solid ratio of 10:1. The extraction rate increased in the range of a $0-50 \%$ volume ratio and decreased in the range of $50-60 \%$. It is possible that the excess water content increased the polarity of the mixture and reduced the interaction between the compounds. Therefore, a $50 \%$ DES moisture content was identified as the best choice during subsequent extraction. 


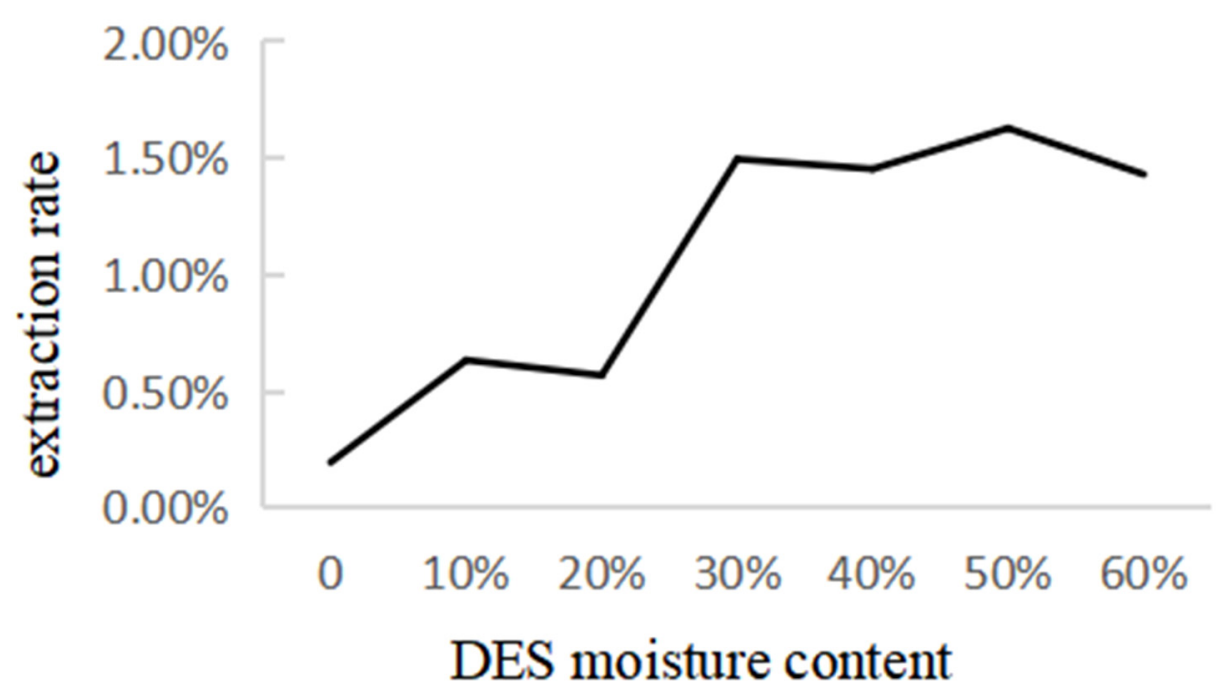

Figure 5. Effect of DES moisture content on the extraction yield of coumarins.

On the basis of the preliminary single-factor experiments, the extraction process parameters were optimized by BBD with the ratio of liquid to solid, extraction time, ultrasonic temperature, and DES moisture content as four independent variables. The total extraction rate of 7 coumarin compounds was used as the response of the design experiment. Regression analysis was performed on the experimental data and additional validation experiments were performed to verify the effectiveness of the statistical experimental strategy. Software Design-Expert 12 was used to generate and evaluate experimental designs.

\subsection{HPLC Conditions and Method Validation}

The HPLC system consists of a Waters quad gradient high-performance liquid chromatography (ACQUITY Arc), a 122 Rheodyne injector (20 $\mu \mathrm{L}$ sample loop), and a full wavelength (200-600nm) diode array detector. The chromatographic analysis was performed on a C18 column $(4.6 \times 250 \mathrm{~mm}, 5.0 \mu \mathrm{m})$. The linear gradient elution was performed used methanol (A) and water (B) as mobile phases. The gradient elution procedure was as follows: 0-5 min: A-B (35:65), $15 \mathrm{~min}:$ A-B (65:35), $17 \mathrm{~min}: \mathrm{A}-\mathrm{B}$ (85:15), $30 \mathrm{~min}: \mathrm{A}-\mathrm{B}$ (90:10), 35 min: A-B (35:65), 37 min: A-B (35:65). The detection wavelength was set at $268 \mathrm{~nm}$, the flow rate was $1 \mathrm{~mL} / \mathrm{min}$, the column temperature was $30^{\circ} \mathrm{C}$, and the injection volume was $10 \mu \mathrm{L}$. Sampling was started $10 \mathrm{~min}$ after system equilibrium, and all samples were analyzed by HPLC after passing through a $0.45 \mu \mathrm{m}$ microporous membrane. The HPLC chromatogram of 7 coumarin standard substances and 7 coumarin compounds extracted from $A$. dahurica are shown in Figure 6.

The quantitative analysis of 7 coumarins in $A$. dahurica was verified by method validation. The linearity, precision, repeatability, and stability were verified. The calibration curves of 7 coumarins were performed with 6 standard solutions of different concentrations in triplicate. All calibration curves were well linear with high correlation coefficients $\left(\mathrm{R}^{2}>0.9948\right)$ over the test range. The accuracy of the method was determined by intra-day and inter-day testing. Intra-day testing means the same sample was analyzed 6 times in the same day. Inter-day test was repeated testing of 3 samples obtained by the same extraction method for 3 consecutive days. The relative standard deviations of intra-day and inter-day precision were less than $1.24 \%$ and $2.13 \%$, respectively. Six replicates of the same sample were prepared and analyzed for the repeatability test. In stability tests, the same sample was stored at room temperature and analyzed repeatedly at $0,4,6,8,12$, and $24 \mathrm{~h}$. The repeatability expressed by relative standard deviation was less than $1.37 \%$, and the stability was less than $1.23 \%$. The results showed that the established method was accurate and 
sensitive for the quantitative analysis of 7 components of A. dahuricae. All of the above data are shown in Table 2.
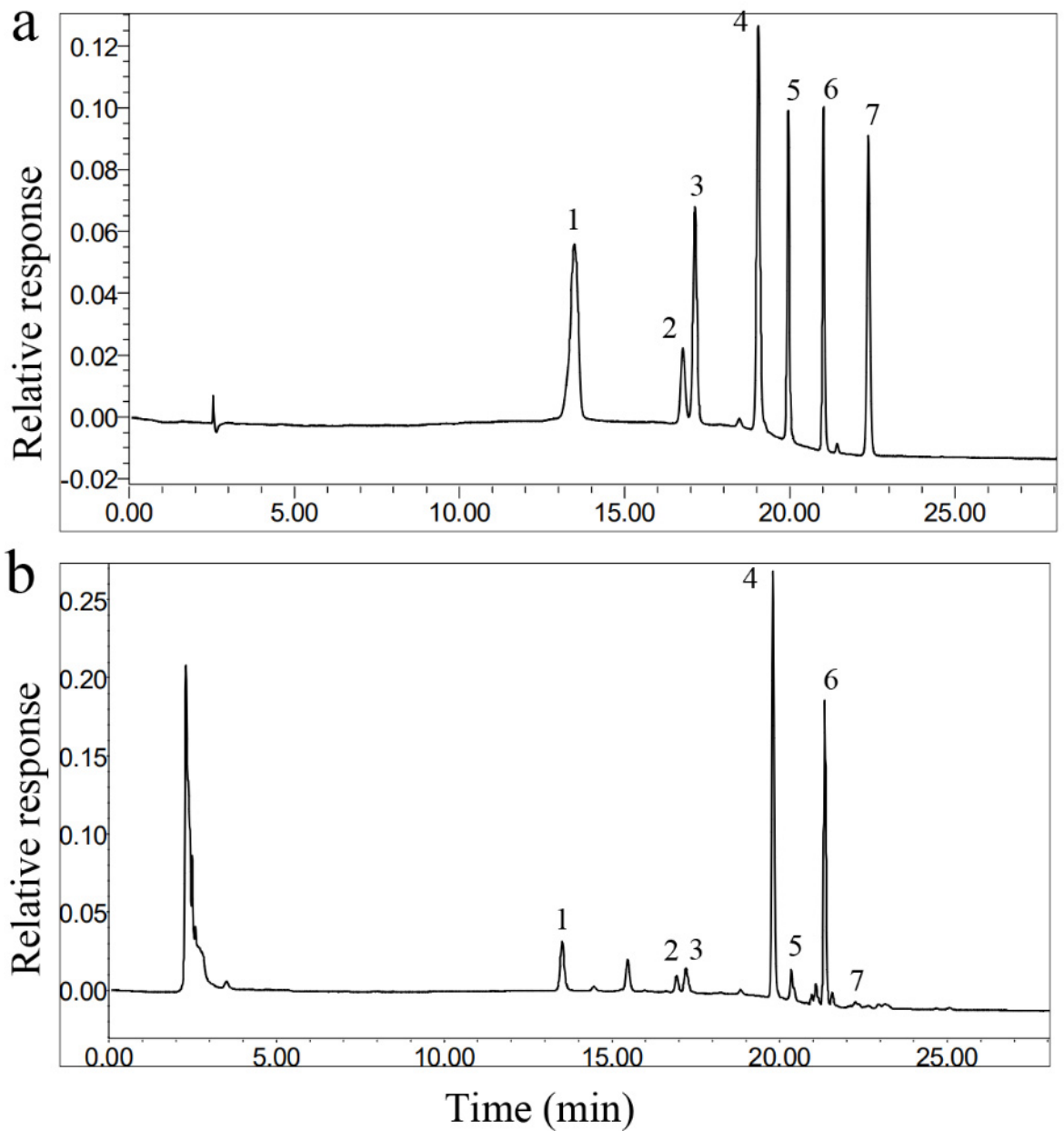

Figure 6. The typical HPLC chromatograms: (a) 7 coumarin reference standards and (b) A. dahurica sample (1. xanthotoxol, $13.48 \mathrm{~min}$; 2. psoralen, $16.76 \mathrm{~min}$; 3. byakangelicin, $17.13 \mathrm{~min}$; 4 . bergapten, $19.04 \mathrm{~min}$; 5. oxypeucedanin, $19.95 \mathrm{~min}$; 6. imperatorin, $21.02 \mathrm{~min}$; and 7. isoimperatorin, $22.38 \mathrm{~min}$ ) and separation degree of chromatographic peak: $5.86 \%, 1.27 \%, 4.17 \%, 1.87 \%, 3.36 \%, 1.82 \%$.

Table 2. Validation of linear regression equation, linear range, precision, repeatability, and stability of 7 coumarins.

\begin{tabular}{|c|c|c|c|c|c|c|c|c|}
\hline \multirow[b]{2}{*}{ No. } & \multirow[b]{2}{*}{ Analyte } & \multirow[b]{2}{*}{ Regression Equation } & \multirow[b]{2}{*}{$\mathbf{R}^{2}$} & \multirow{2}{*}{$\begin{array}{l}\text { Linear Range } \\
(\mathrm{mg} / \mathrm{mL})\end{array}$} & \multicolumn{2}{|c|}{ Precision } & \multirow{2}{*}{$\begin{array}{c}\text { Repeatability } \\
\text { RSD (\%) }\end{array}$} & \multirow{2}{*}{$\begin{array}{l}\text { Stability } \\
\text { RSD (\%) }\end{array}$} \\
\hline & & & & & $\begin{array}{l}\text { Intra-Day } \\
\text { RSD (\%) }\end{array}$ & $\begin{array}{l}\text { Inter-Day } \\
\text { RSD (\%) }\end{array}$ & & \\
\hline 1 & Xanthotoxol & $Y=9286.6 X+43348$ & 0.9948 & $0.040-0.200$ & 0.26 & 1.46 & 1.13 & 0.22 \\
\hline 2 & Psoralen & $Y=2232.3 X-8340.4$ & 0.9998 & $0.036-0.180$ & 0.54 & 1.74 & 1.37 & 1.23 \\
\hline 3 & Byakangelicin & $Y=5192.5 X-3041.4$ & 0.9996 & $0.040-0.200$ & 0.47 & 1.62 & 0.57 & 1.09 \\
\hline 4 & Bergapten & $Y=8584.5 X+21114$ & 0.9998 & $0.040-0.200$ & 0.83 & 2.13 & 0.47 & 0.68 \\
\hline 5 & Oxypeucedanin & $Y=4801.5 X+2149.1$ & 0.9996 & $0.040-0.200$ & 1.24 & 1.82 & 0.44 & 0.34 \\
\hline 6 & Imperatorin & $Y=4442.6 X-7511.1$ & 0.9999 & $0.040-0.200$ & 0.20 & 1.78 & 0.45 & 0.94 \\
\hline 7 & Isoimperatorin & $Y=5522.3 X-10479$ & 0.9999 & $0.040-0.200$ & 0.23 & 1.57 & 0.47 & 0.95 \\
\hline
\end{tabular}

\subsection{Determination of Antioxidant Activity of Plant Extracts}

Oxidation is one of the most important processes in food spoilage. Antioxidants can protect against the harmful effects of free radicals in the body and prevent the oxidation of fats and other food components [25]. The widely documented 1,1-diphenyl-2- 
pyrylhydrazyl (DPPH) radical was used to assess antioxidant activity, because it is a stable free radical that can accept electrons or hydrogen radicals to form stable chemicals [26].

In this study, the antioxidant activities of two different extraction methods were compared (75\% ethanol traditional heating reflux extraction and DES ultrasonic extraction). The concentration of the solution varied from 0.1 to $27 \mathrm{mg} / \mathrm{mL}$ for each sample. In addition, the vitamin $\mathrm{C}$ (VC) solution of the corresponding concentration was prepared by deionized water as a control test of antioxidant activity. The absorbance was measured at $517 \mathrm{~nm}$ relative to the blank. The percentage of scavenging activity was calculated as follows: $\left(1-\left(A_{1}-A_{2}\right) / A_{0}\right) \times 100 \%$, where $A_{0}$ is the absorbance of the control, $A_{1}$ is the absorbance of the sample, and $\mathrm{A}_{2}$ is the absorbance of the blank sample without DPPH free radical. The scavenging activity of the sample is expressed as the $\mathrm{IC}_{50}$ value, which is the concentration required to remove 50\% DPPH free radicals [27].

\subsection{Microstructure of Plant Material}

In order to study the microscopic effects of different extraction methods on the fragmentation degree of $A$. dahuricae powder, the microstructure changes in the powder before and after extraction by three different extraction methods were observed by scanning electron microscope. The dried powder was secured to the sample table with double-sided tape and gilded. Then the morphology of the powders extracted with different solvents was observed by scanning electron microscope at $10 \mathrm{kV}$ accelerating voltage.

\section{Results and Discussion}

\subsection{Screening of DESs}

The total yield of coumarins in each extraction solvent was the sum of seven kinds of coumarin compounds. The results showed that the total extraction rate of seven coumarin compounds was affected by different solvents. In order to understand the advantages of DESs in extracting coumarin compounds from $A$. dahurica, the extraction rates of different organic solvents (methanol and $75 \%$ ethanol) and different DESs were compared. As shown in Figure 7, compared with the traditional extraction method, the extraction rate of DES-3 was significantly higher than that of other DES solvents and traditional organic solvents.

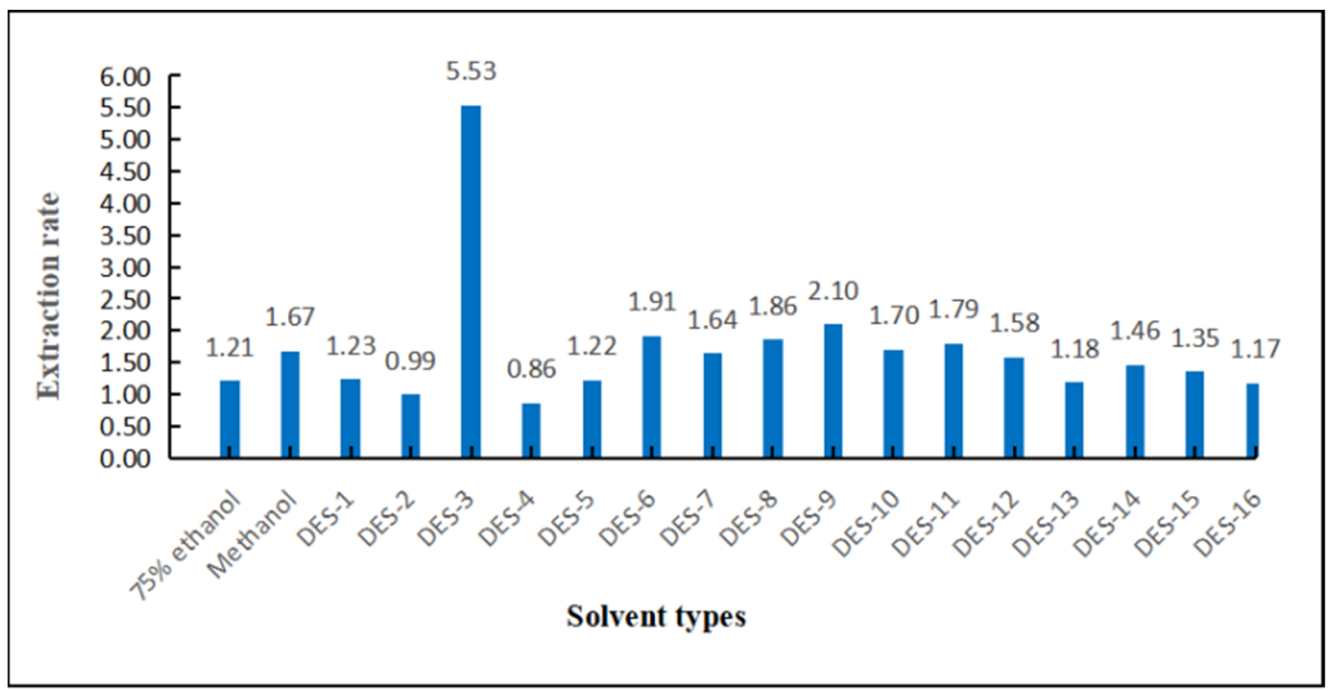

Figure 7. The yield of total coumarins extracted with different organic solvents and DES. Note: The yield of total coumarins was the sum of 7 kinds of coumarins.

The composition of DES could influence the hydrogen bond between the hydrogen bond donor and the hydrogen bond acceptor, thus determining its viscosity and polarity. The high viscosity of DES restricts its application in extraction compared to conventional solvents. High viscosity may reduce extraction efficiency because of slow mass transfer, 
whereas low-viscosity DES results in high diffusivity and therefore improved extraction performance. Most DESs showed a low total extraction rate for the seven coumarins, but DES prepared with choline chloride, citric acid, and water at a molar ratio of 1:1:2 produced a higher extraction efficiency. This may be because citric acid has higher hydrogen-bonding capacity and more electrostatic interaction with choline chloride than other hydrogen bond donors. Therefore, this type of DES was chosen as the best extraction solvent for coumarins compounds and applied in further tests based on the initial screening results.

\subsection{Optimization of the Extraction Conditions by Response Surface Methodology}

The above extraction studies show that the molar ratio of choline chloride, citric acid, and water of 1:1:2 was the best DES. In order to obtain the best extraction rate, RSM was used to optimize several extraction conditions that affected the extraction rate. Four-factor and three-level BBD were used to investigate the influence of four independent variablesliquid-solid ratio (A), extraction temperature (B), extraction time (C), and DES moisture content (D)—on the extraction yield (Y), which is shown in Table 3.

Table 3. Factors and levels in response surface analysis.

\begin{tabular}{lccc}
\hline \multicolumn{1}{c}{ Factors } & \multicolumn{1}{c}{ Level } & \\
& $\mathbf{- 1}$ & $\mathbf{0}$ & $\mathbf{1}$ \\
\hline A Liquid-solid ratio $(\mathrm{mg} / \mathrm{mL})$ & 10 & 20 & 30 \\
B Extraction temperature $\left({ }^{\circ} \mathrm{C}\right)$ & 40 & 50 & 60 \\
C Extraction time $(\mathrm{min})$ & 30 & 40 & 50 \\
D DES moisture content $(\%)$ & 40 & 50 & 60 \\
\hline
\end{tabular}

The extraction process parameters of ultrasonic assisted DES extraction were systematically investigated, and the optimal extraction conditions of coumarin compounds in A. dahurica were determined. The solid-liquid ratio, ultrasonic temperature, extraction time and DES moisture content were investigated by single factor test. As shown in Table 4, on the basis of single factor test, RSM and BBD were used to determine the optimal combination of solid-liquid ratio, extraction temperature, extraction time and DES moisture content.

Table 4. Experimental order, variable levels, and response values in Box-Behnken designs.

\begin{tabular}{|c|c|c|c|c|c|}
\hline Run & $\begin{array}{c}\text { Liquid-Solid } \\
\text { Ratio (A, mL/g) }\end{array}$ & $\begin{array}{c}\text { Extraction } \\
\text { Temperature }\left(\mathrm{B},{ }^{\circ} \mathrm{C}\right)\end{array}$ & $\begin{array}{c}\text { Extraction } \\
\text { Time }(C, \text { min })\end{array}$ & $\begin{array}{l}\text { DES Moisture } \\
\text { Content (D, \%) }\end{array}$ & $\begin{array}{l}\text { Total Extraction } \\
\text { Yields (mg/g) }\end{array}$ \\
\hline 1 & 0 & -1 & -1 & 0 & 0.92 \\
\hline 2 & 0 & 0 & 1 & -1 & 1.17 \\
\hline 3 & 0 & 0 & -1 & 1 & 1.07 \\
\hline 4 & -1 & 0 & 1 & 0 & 1.13 \\
\hline 5 & -1 & 0 & 0 & -1 & 1.07 \\
\hline 6 & 0 & 1 & 1 & 0 & 1.31 \\
\hline 7 & 0 & 0 & 0 & 0 & 1.02 \\
\hline 8 & 0 & 0 & 1 & 1 & 1.24 \\
\hline 9 & -1 & 1 & 0 & 0 & 1.26 \\
\hline 10 & 1 & 0 & 0 & -1 & 0.5 \\
\hline 11 & 1 & 0 & 1 & 0 & 0.71 \\
\hline 12 & 1 & 0 & -1 & 0 & 0.75 \\
\hline 13 & 0 & 1 & -1 & 0 & 1.26 \\
\hline 14 & 0 & 0 & -1 & -1 & 0.88 \\
\hline 15 & 0 & 1 & 0 & -1 & 0.46 \\
\hline 16 & 0 & 0 & 0 & 0 & 0.94 \\
\hline 17 & 1 & 0 & 0 & 1 & 1.07 \\
\hline 18 & 0 & 0 & 0 & 0 & 0.88 \\
\hline 19 & 0 & -1 & 0 & 1 & 0.95 \\
\hline 20 & 0 & 1 & 0 & 1 & 1.04 \\
\hline
\end{tabular}


Table 4. Cont.

\begin{tabular}{cccccc}
\hline Run & $\begin{array}{c}\text { Liquid-Solid } \\
\text { Ratio (A, mL/g) }\end{array}$ & $\begin{array}{c}\text { Extraction } \\
\left.\text { Temperature (B, }{ }^{\circ} \mathbf{C}\right)\end{array}$ & $\begin{array}{c}\text { Extraction } \\
\text { Time (C, min) }\end{array}$ & $\begin{array}{c}\text { DES Moisture } \\
\text { Content (D, \%) }\end{array}$ & $\begin{array}{c}\text { Total Extraction } \\
\text { Yields (mg/g) }\end{array}$ \\
\hline 21 & -1 & 0 & -1 & 0 & 0.95 \\
22 & 1 & -1 & 0 & 0 & 0.68 \\
23 & 0 & -1 & 0 & -1 & 0.52 \\
24 & 1 & 1 & 0 & 0 & 0.85 \\
25 & 0 & -1 & 1 & 0 & 1.19 \\
26 & -1 & 0 & 0 & 1 & 0.98 \\
27 & -1 & -1 & 0 & 0 & 0.89 \\
28 & 0 & 0 & 0 & 0 & 1.09 \\
29 & 0 & 0 & 0 & 0 & 1.11 \\
\hline
\end{tabular}

The above tests were performed in three replicates. Design-Expert 12 was used to carry out multiple regression of BBD data to obtain the second-order polynomial model.

\subsection{Fitting the Response Surface Model}

The effects of four parameters on the yield of total coumarins in A. dahurica were investigated at the levels of $-1,0$, and +1 . A total of 29 different tests were carried out, and the mean values were fitted using a second-order polynomial model, as follows:

$$
\begin{gathered}
\mathrm{Y}=1.01-0.14 \mathrm{~A}+0.086 \mathrm{~B}+0.077 \mathrm{C}+0.15 \mathrm{D}-0.050 \mathrm{AB}-0.055 \mathrm{AC}+0.17 \mathrm{AD}-0.055 \mathrm{BC}+0.038 \mathrm{BD}- \\
0.030 \mathrm{CD}-0.10 \mathrm{~A}^{2}-0.040 \mathrm{~B}^{2}+0.12 \mathrm{C}^{2}-0.087 \mathrm{D}^{2}
\end{gathered}
$$

Analysis of variance was used to evaluate the optimal conditions for ultrasonicassisted DES extraction and the relationship between the reaction and the variables. Table 5 shows the analysis of variance for the quadratic model. The F-value in analysis of variance ANOVA was used to estimate differences between groups. The F-value represents the significance of the whole fitting equation. The larger the $F$ value is, the more significant the equation is and the better the fitting degree is. The $p$-value is a measure of the size of the difference. $p<0.05$ indicates significant difference. $p<0.01$ indicates extremely significant difference.

Table 5. The analysis of variance (ANOVA) results of the quadratic multiple regression model for total coumarin yield.

\begin{tabular}{ccccccc}
\hline Variables & $\begin{array}{c}\text { Sum of } \\
\text { Squares }\end{array}$ & df & $\begin{array}{c}\text { Mean } \\
\text { Square }\end{array}$ & F-Value & $p$-Value \\
\hline Model & 1.06 & 14 & 0.076 & 2.66 & 0.0388 & significant \\
A-Liquid-solid ratio & 0.25 & 1 & 0.25 & 8.62 & 0.0108 & 0.1005 \\
B-Extraction temperature & 0.088 & 1 & 0.088 & 3.09 & 2.47 & 0.1386 \\
C-Extraction time & 0.071 & 1 & 0.071 & 8.93 & 0.0098 \\
D-DES moisture content & 0.26 & 1 & 0.26 & 0.35 & 0.5636 \\
AB & 0.010 & 1 & 0.010 & 0.42 & 0.5258 \\
AC & 0.012 & 1 & 0.012 & 3.81 & 0.0713 \\
AD & 0.11 & 1 & 0.11 & 0.42 & 0.5258 \\
BC & 0.012 & 1 & 0.012 & 0.20 & 0.6641 \\
BD & 0.006 & 1 & 0.006 & 0.13 & 0.7280 \\
CD & 0.004 & 1 & 0.004 & 2.32 & 0.1501 \\
A $^{2}$ & 0.066 & 1 & 0.066 & 0.36 & 0.5581 \\
B $^{2}$ & 0.010 & 1 & 0.010 & 3.08 & 0.1013 \\
C $^{2}$ & 0.088 & 1 & 0.088 & 1.73 & 0.2095 \\
D $^{2}$ & 0.049 & 1 & 0.049 & & \\
Residual & 0.40 & 14 & 0.029 & & \\
Lake of fit & 0.36 & 10 & 0.036 & 3.78 & 0.1058 \\
$\mathrm{R}^{2}$ & 0.974 & & & & Not significant \\
Adj R $^{2}$ & 0.817 & & & & \\
\hline
\end{tabular}

According to the F-value of the analysis of variance in Table 3, the influence degree of the four factors on the extraction rate of coumarins of $A$. dahurica was DES moisture content (D) $>$ liquid-solid ratio (A) > extraction temperature (B) > extraction time (C), which is 
visually expressed by the Pareto diagram in Figure 8. The $p$-value of the model $<0.05$, indicating that the regression relationship between the total rate of coumarins of $A$. dahuricae and their respective variables is significant, which can better simulate the real surface. The loss of fitting term $p=0.1058>0.05$, and the influence was not significant, indicating that the experimental data and the model were significantly consistent. This model can be used to analyze and predict the extraction rate of coumarins in A. dahuricae, and it is true and reliable. In this model, primary term $\mathrm{D}$ had a highly significant effect on the total extraction rate of coumarins $(p<0.01)$, and primary term A had a significant effect on the total extraction rate of coumarins in A. dahuricae $(p<0.05)$; the interaction effect was not significant. The correlation coefficient $\mathrm{R}^{2}=0.974$ and the adjusted determination coefficient adjustment $\mathrm{R}^{2}$ (Adj $\mathrm{R}^{2}$ ) $=0.817$, indicating that this model can be used to explain the change in the extraction rate of coumarin components in $81.7 \%$ of $A$. dahuricae.

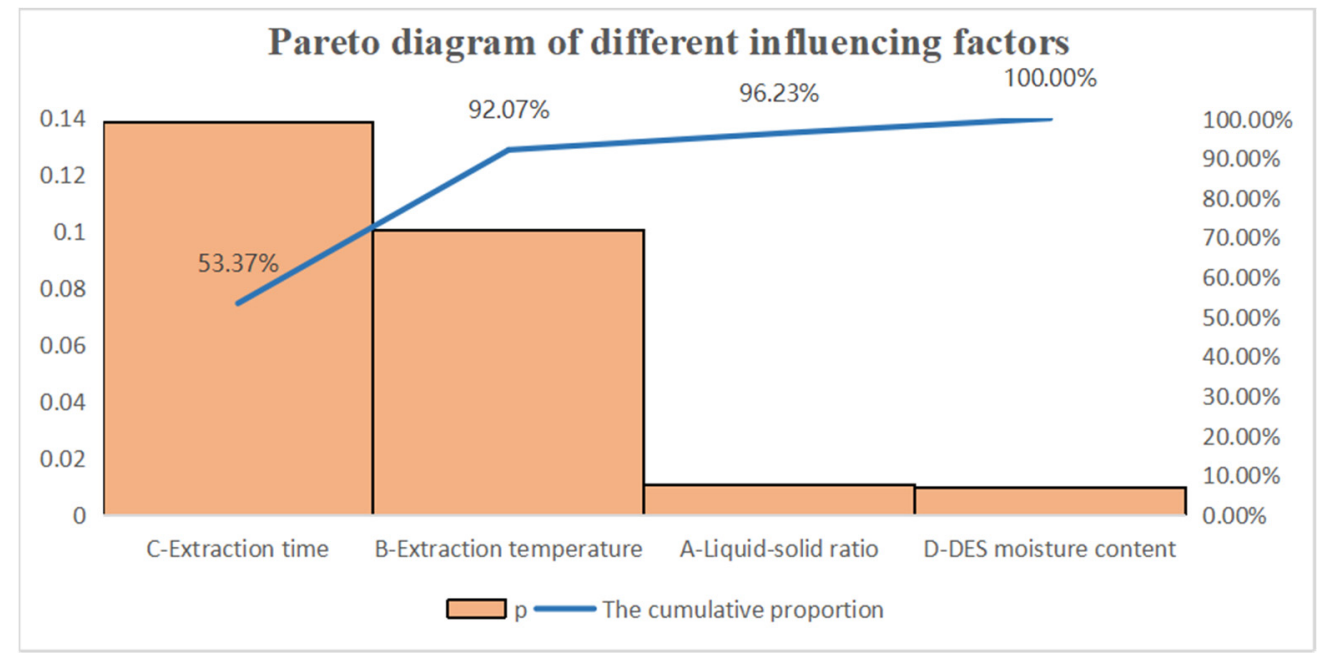

Figure 8. Pareto diagram of different influencing factors.

\subsection{Verification of Predictive Model}

Using Design-Expert software, the optimal values of independent and dependent variables were as follows: liquid-solid ratio (A) was $10 \mathrm{~mL} / \mathrm{g}$, extraction temperature (B) was $59.85^{\circ} \mathrm{C}$, extraction time (C) was $50 \mathrm{~min}$, and DES moisture content (D) was $49.28 \%$. The maximum predicted extraction rate was $1.34 \%$. Under the optimal extraction conditions, three verification experiments were carried out, and the average extraction rate was $1.18 \%$. The results showed that the regression model was appropriate for predicting the extraction yield of coumarins from $A$. dahuricae. In addition, compared with the reported methods, the extraction time and solid-liquid ratio in this study were greatly reduced. The traditional solvent extraction time of coumarins is $4.23 \mathrm{~h}$. Compared to the traditional extraction time, the extraction time used in this study was reduced by 5 times, only $50 \mathrm{~min}$. Therefore, this model can save cost and is suitable for the optimization of the ultrasonic-assisted extraction process based on DESs.

\subsection{D Response Surface}

For the response surface test, the three-dimensional surface of the interaction term of two factors is shown in Figure 9. The steeper the slope change of the 3D surface, the denser the contour line, and more like an oval or saddle shape, the more significant the interaction between the two factors. As shown in Figure 9, the contour lines of the $A B, A C$, $\mathrm{AD}, \mathrm{BC}, \mathrm{BD}$, and $\mathrm{CD}$ interaction terms were basically saddle-shaped or elliptic, and the contour map of the AD interaction terms was typical elliptic. The contour map of the AC, $\mathrm{AD}, \mathrm{BC}, \mathrm{BD}$, and $\mathrm{CD}$ interaction terms was elliptic, but the slope change of the 3D surface of the interaction terms in group $\mathrm{BD}$ was relatively gentle compared to those in groups $\mathrm{AB}$, $\mathrm{AC}, \mathrm{AD}$, and $\mathrm{BC}$. This is consistent with the results of the analysis of variance in Table 5. 

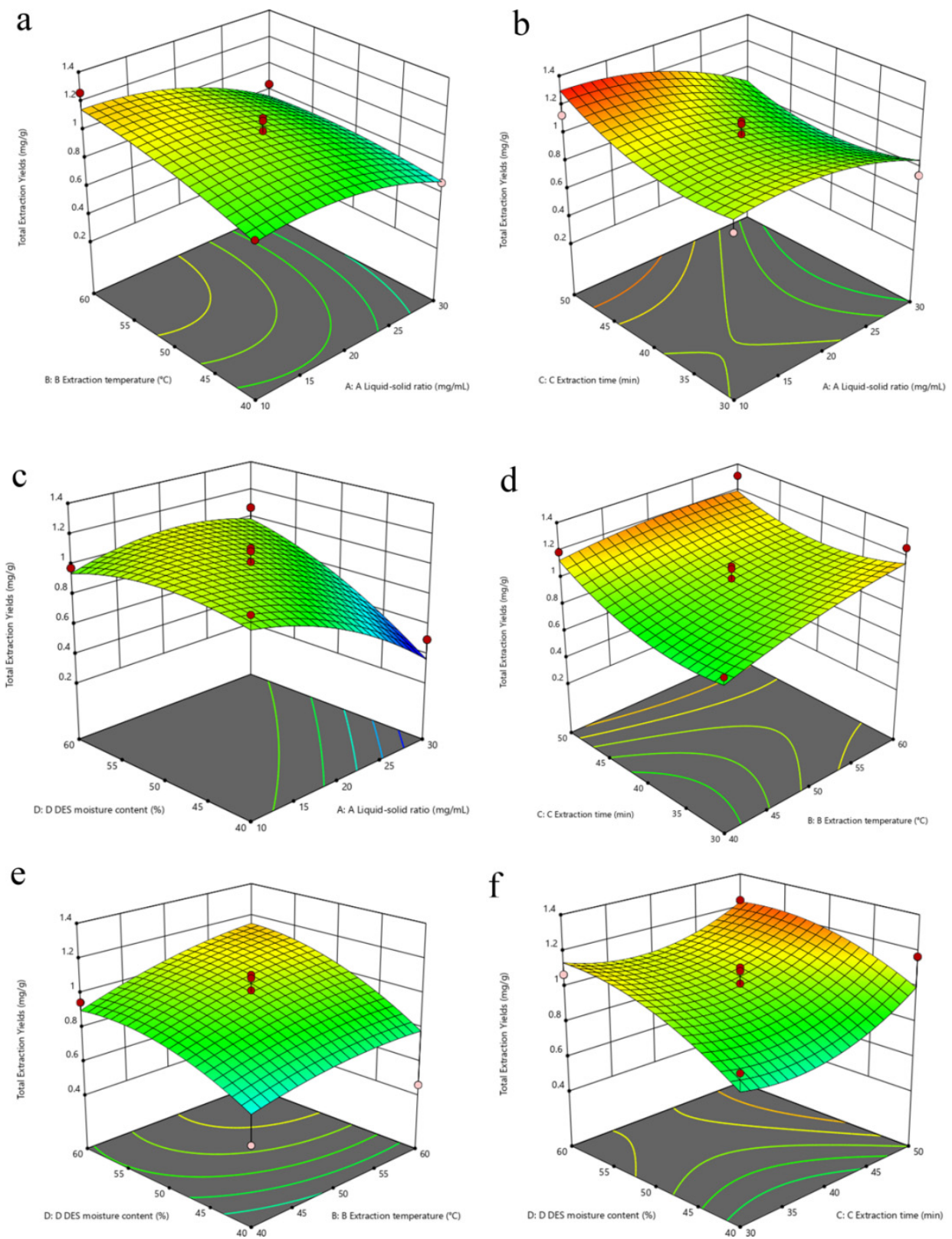

Figure 9. 3D response surface. Notes: (a) the reciprocal response of $A$ and $B,(\mathbf{b})$ the reciprocal response of $A$ and $C,(c)$ the reciprocal response of $A$ and $D,(d)$ the reciprocal response of $B$ and $C$, (e) the reciprocal response of $\mathrm{B}$ and $\mathrm{D},(\mathbf{f})$ the reciprocal response of $\mathrm{C}$ and $\mathrm{D}$.

\subsection{Microstructure of Plant Material}

The residues of different extraction methods were observed by scanning electron microscopy (SEM). As shown in Figure 10, it can be seen that the cells of A. dahurica medicinal materials obtained by DES ultrasonic assisted treatment were the most seriously broken, indicating that DES had the highest efficiency in the treatment of A. dahurica. This result is the same as that shown in Section 3.1. The degree of cell fragmentation was proportional to the extraction rate. By contrast, the outer surface of the sample powder was significantly cracked by pulsed ultrasonic treatment, and loose and broken structures could be observed. This is similar to what Sukor et al. observed when extracting phenolic acids using ultrasonic processing of an ionic liquid probe [28], and Chen et al. used ultrasoundassisted extraction methods for imperatorin and isoimperatorin from A. dahurica roots [22]. 

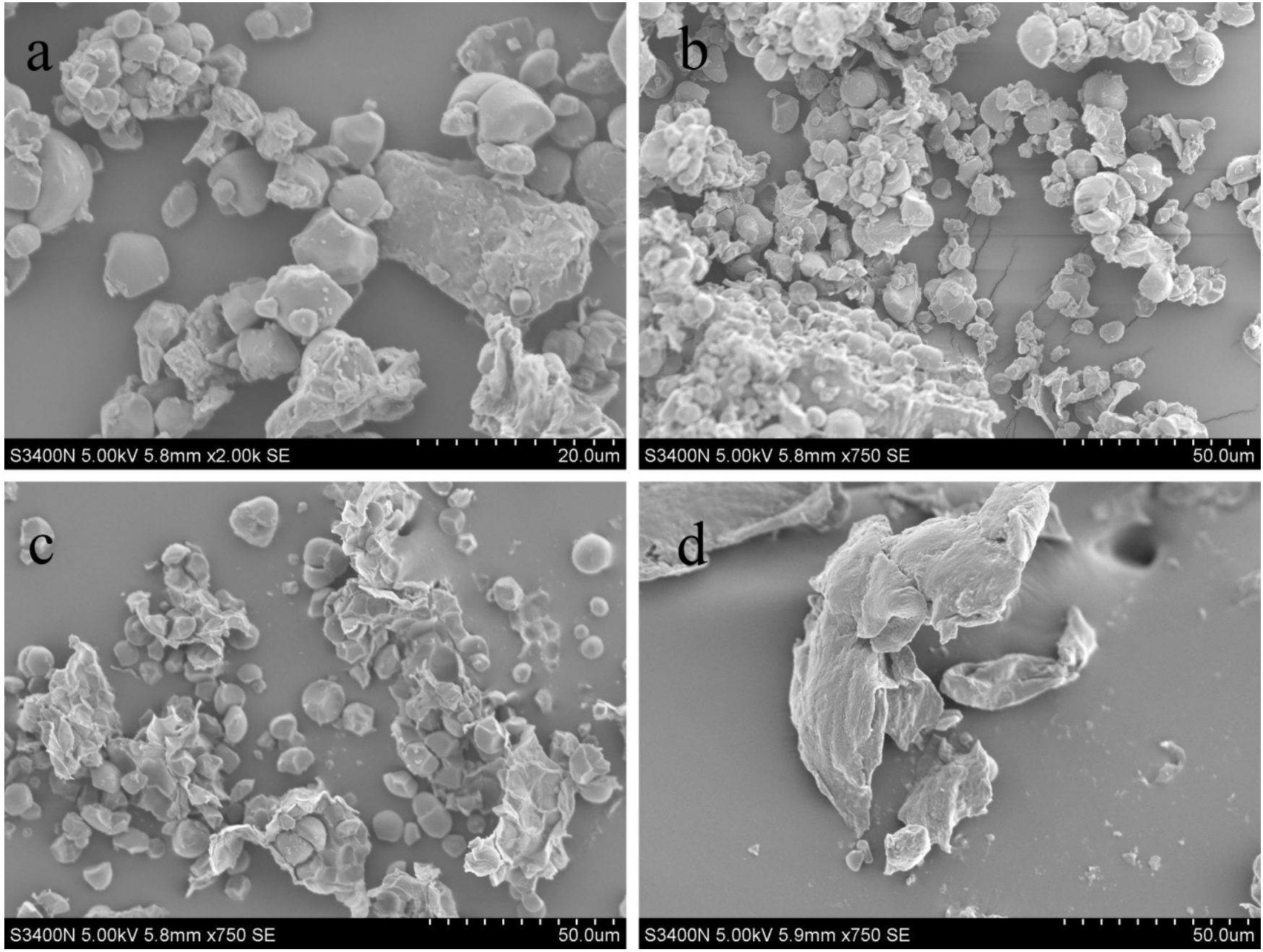

Figure 10. The field emission scanning electron microscope images: (a) unextracted A. dahurica powder, (b) 75\% ethanol ultrasound, (c) methanol ultrasonic, and (d) the selected DES ultrasound.

Organic solvent extraction, microwave-assisted extraction, and ultrasonic extraction have been widely used in the extraction of single medicinal materials [29]. In addition, Feng et al. combined ultrasonic-assisted extraction and microwave-assisted extraction technology to rapidly determine the essential oil of $A$. dahurica [30]. Ultrasonic-assisted extraction is a technique based on cavitation phenomena or mechanical waves generated by highfrequency impulses [31]. This force can break down plant cell walls and reduce particle size, promote swelling, and extract solvents to penetrate cells and release bioactive compounds from vacuoles [32,33]. Therefore, ultrasound-assisted extraction of coumarins compounds from A. dahuricae with DESs can replace the traditional organic solvent extraction method, becoming a green and efficient extraction method.

\subsection{Antioxidant Activity of Extracts}

DPPH has been widely used to determine the antioxidant capacity of biological samples, pure compounds, and extracts in vitro. This method is simple and can be used to evaluate the antioxidant activity of the samples [28]. With VC as the control, the DPPH radical scavenging activities of the two different treated solutions are shown in Figure 11. 


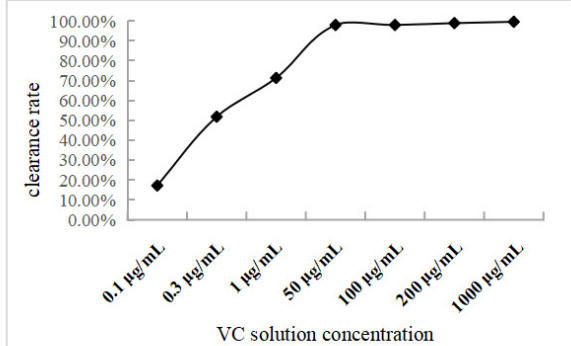

a

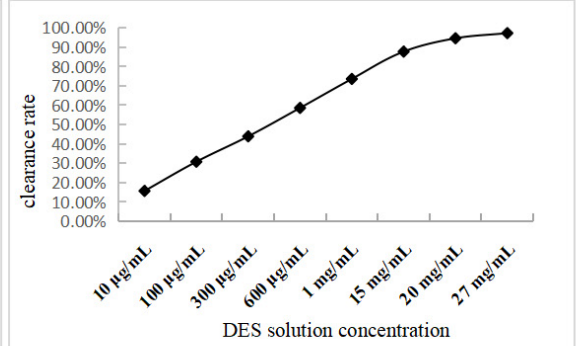

$\mathrm{b}$

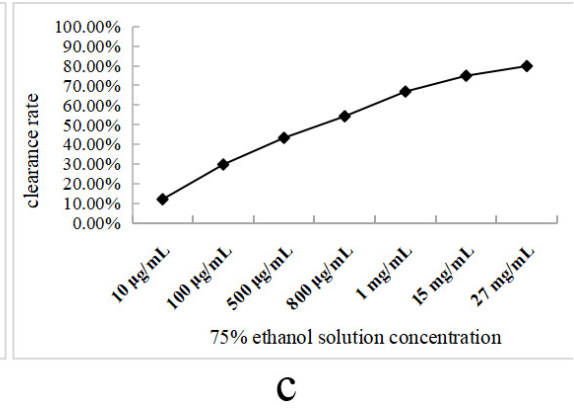

C

Figure 11. Comparison of DPPH radical scavenging activity in different solutions. (a) VC reference solution; (b) DES solution; (c) 75\% ethanol solution.

As shown in Figure 11, with the increase in the concentration of different sample solutions, the scavenging ability of antioxidants in different solutions on DPPH free radical gradually increased, and gradually leveled off after reaching a certain concentration. The clearance rate of VC to DPPH tended to be stable when the concentration was $50 \mu \mathrm{g} / \mathrm{mL}$, and reached the maximum at $100 \mu \mathrm{g} / \mathrm{mL}$, with a maximum clearance rate was $99.54 \%$. The DPPH clearance rate of DES extract tended to be stable at $20 \mathrm{mg} / \mathrm{mL}$, and the maximum clearance rate was $97.22 \%$. When reflux extraction with a concentration of $75 \%$ ethanol reached the specified concentration, its clearance rate was lower than that of DES solution (79.83\%). According to SPSS software analysis, the $\mathrm{IC}_{50}$ values of VC extract, DES extract, and $75 \%$ ethanol heated reflux extract were $0.289 \mu \mathrm{g} / \mathrm{mL}, 0.477 \mathrm{mg} / \mathrm{mL}$, and $0.772 \mathrm{mg} / \mathrm{mL}$, respectively. In conclusion, $\mathrm{VC}$ control solution has the strongest DPPH radical scavenging ability. The scavenging ability of DES extract was better than that of $75 \%$ ethanol extract. The antioxidant capacity of $75 \%$ ethanol extract was not as good as that of DES solution, but it still had a significant effect.

\section{Conclusions}

This study aimed to provide a more green, efficient, economic, and environmentally protective target ingredient extraction method, which could better promote the in-depth development of Chinese herbal $A$. dahurica resources and provide data support for the development of green chemistry and the study of natural products in China. DESs were used to extract coumarin compounds from A. dahurica with ultrasonic assistance. A rapid and green extraction method for coumarins such as xanthotoxol, psoralen, byakangelicin, bergapten, oxypeucedanin, imperatorin, and isoimperatorin from $A$. dahuricae was developed. Experiments showed that the ultrasonic-assisted DES system is an effective system for extracting coumarin compounds from A. dahurica, which solves the problems of environmental pollution and solvent residue in extracting natural active ingredients of traditional Chinese medicine with traditional organic solvents.

Author Contributions: Conceptualization, T.W. and Q.L.; data curation, T.W.; formal analysis, T.W.; investigation, T.W. and Q.L.; methodology, T.W. and Q.L.; project administration, Q.L.; supervision, T.W. and Q.L.; validation, T.W.; writing-original draft, T.W.; writing—review and editing, T.W. and Q.L. All authors have read and agreed to the published version of the manuscript.

Funding: This work was supported by the Discipline Construction Fund Project of Gansu Agricultural University (GSAU-XKJS-2018-086), the National Science Foundation of China (31860102), Young Talents introduction projects (GSU-RCZX201704), the research program sponsored by Gansu Provincial Key Laboratory of Aridland Crop Science, Gansu Agricultural University (No.GSCS-2018-3), and the Outstanding Graduate Student Innovation Star Project in Gansu Province (2021CXZX-399).

Institutional Review Board Statement: Not applicable.

Informed Consent Statement: Not applicable. 
Data Availability Statement: The data presented in this study are available on request from the corresponding author.

Conflicts of Interest: There are no conflict of interest to declare.

Sample Availability: Samples of the compounds are available from the authors.

\section{References}

1. Bai, Y.; Li, D.; Zhou, T.; Qin, N.; Li, Z.; Yu, Z.; Hua, H. Coumarins from the roots of Angelica dahurica with antioxidant and antiproliferative activities. J. Funct. Foods 2016, 20, 453-462. [CrossRef]

2. Chen, Y.; Fan, G.; Chen, B.; Xie, Y.; Wu, H.; Wu, Y.; Yan, C.; Wang, J. Separation and quantitative analysis of coumarin compounds from Angelica dahurica (Fisch. ex Hoffm) Benth. et Hook. $\mathrm{f}$ by pressurized capillary electrochromatography. J. Pharm. Biomed. Anal. 2006, 41, 105-116. [CrossRef] [PubMed]

3. Kim, S.H.; Kang, S.S.; Kim, C.M. Coumarin glycosides from the roots of Angelica dahurica. Arch. Pharmacal Res. 1992, 15, 73-77. [CrossRef]

4. Zheng, X.; Zhang, X.; Sheng, X.; Yuan, Z.; Yang, W.; Wang, Q.; Zhang, L. Simultaneous characterization and quantitation of 11 coumarins in Radix Angelicae Dahuricae by high performance liquid chromatography with electrospray tandem mass spectrometry. J. Pharm. Biomed. Anal. 2010, 51, 599-605. [CrossRef]

5. Fu, X.; Wang, D.; Belwal, T.; Xu, Y.; Li, L.; Luo, Z. Sonication-synergistic natural deep eutectic solvent as a green and efficient approach for extraction of phenolic compounds from peels of Carya cathayensis Sarg. Food Chem. 2021, 355, 129577. [CrossRef]

6. Obluchinskaya, E.; Pozharitskaya, O.; Zakharova, L.; Daurtseva, A.; Flisyuk, E.; Shikov, A. Efficacy of Natural Deep Eutectic Solvents for Extraction of Hydrophilic and Lipophilic Compounds from Fucus vesiculosus. Molecules 2021, 26, 4198. [CrossRef] [PubMed]

7. Boyko, N.; Zhilyakova, E.; Malyutina, A.; Novikov, O.; Pisarev, D.; Abramovich, R.; Potanina, O.; Lazar, S.; Mizina, P.; SahaidakNikitiuk, R. Studying and Modeling of the Extraction Properties of the Natural Deep Eutectic Solvent and Sorbitol-Based Solvents in Regard to Biologically Active Substances from Glycyrrhizae Roots. Molecules 2020, 25, 1482. [CrossRef] [PubMed]

8. Dai, Y.; Witkamp, G.-J.; Verpoorte, R.; Choi, Y.H. Tailoring properties of natural deep eutectic solvents with water to facilitate their applications. Food Chem. 2015, 187, 14-19. [CrossRef]

9. Zhang, L.; Wang, M. Optimization of deep eutectic solvent-based ultrasound-assisted extraction of polysaccharides from Dioscorea opposita Thunb. Int. J. Biol. Macromol. 2017, 95, 675-681. [CrossRef]

10. Bi, W.; Tian, M.; Row, K.H. Evaluation of alcohol-based deep eutectic solvent in extraction and determination of flavonoids with response surface methodology optimization. J. Chromatogr. A 2013, 1285, 22-30. [CrossRef]

11. Peng, X.; Duan, M.H.; Yao, X.H.; Zhang, Y.H.; Zhao, C.G.; Zu, Y.G.; Fu, Y.J. Green extraction of five target phenolic acids from Lonicerae japonicae Flos with deep eutectic solvent. Sep. Purif. Technol. 2016, 157, 249-257. [CrossRef]

12. Skarpalezos, D.; Detsi, A. Deep Eutectic Solvents as Extraction Media for Valuable Flavonoids from Natural Sources. Appl. Sci. 2019, 9, 4169. [CrossRef]

13. Yang, G.-Y.; Song, J.-N.; Chang, Y.-Q.; Wang, L.; Zheng, Y.-G.; Zhang, D.; Guo, L. Natural Deep Eutectic Solvents for the Extraction of Bioactive Steroidal Saponins from Dioscoreae Nipponicae Rhizoma. Molecules 2021, 26, 2079. [CrossRef] [PubMed]

14. Duan, L.; Dou, L.-L.; Guo, L.; Li, P.; Liu, E.-H. Comprehensive evaluation of deep eutectic solvents in extraction of bioactive natural products. ACS Sustain. Chem. Eng. 2016, 4, 2405-2411. [CrossRef]

15. Wang, Y.; Hu, Y.; Wang, H.; Tong, M.; Gong, Y. Green and enhanced extraction of coumarins from Cortex Fraxini by ultrasoundassisted deep eutectic solvent extraction. J. Sep. Sci. 2020, 43, 3441-3448. [CrossRef] [PubMed]

16. Razboršek, M.I.; Ivanović, M.; Krajnc, P.; Kolar, M. Choline Chloride Based Natural Deep Eutectic Solvents as Extraction Media for Extracting Phenolic Compounds from Chokeberry (Aronia melanocarpa). Molecules 2020, 25, 1619. [CrossRef]

17. Ahmad, I.; Arifianti, A.E.; Sakti, A.S.; Saputri, F.C.; Mun'im, A. Simultaneous Natural Deep Eutectic Solvent-Based UltrasonicAssisted Extraction of Bioactive Compounds of Cinnamon Bark and Sappan Wood as a Dipeptidyl Peptidase IV Inhibitor. Molecules 2020, 25, 3832. [CrossRef]

18. Aryati, W.D.; Nadhira, A.; Febianli, D.; Fransisca, F.; Mun'im, A. Natural deep eutectic solvents ultrasound-assisted extraction (NADES-UAE) of trans-cinnamaldehyde and coumarin from cinnamon bark [Cinnamomum burmannii (Nees T. Nees) Blume]. J. Res. Pharm. 2020, 24, 389-398. [CrossRef]

19. Chen, L.; Jian, Y.; Wei, N.; Yuan, M.; Zhuang, X.; Li, H. Separation and simultaneous quantification of nine furanocoumarins from Radix Angelicae dahuricae using liquid chromatography with tandem mass spectrometry for bioavailability determination in rats. J. Sep. Sci. 2016, 38, 4216-4224. [CrossRef]

20. Pfeifer, I.; Murauer, A.; Ganzera, M. Determination of coumarins in the roots of Angelica dahurica by supercritical fluid chromatography. J. Pharm. Biomed. Anal. 2016, 129, 246-251. [CrossRef]

21. Xu, D.-P.; Zheng, J.; Zhou, Y.; Li, Y.; Li, S.; Li, H.-B. Ultrasound-assisted extraction of natural antioxidants from the flower of Limonium sinuatum: Optimization and comparison with conventional methods. Food Chem. 2017, 217, 552-559. [CrossRef] [PubMed]

22. Chen, Y.; Yang, S.Y.; Li, N.; Zhang, L.J.; Qian, Y. Ultrasound-Assisted Extraction of Imperatorin and Isoimperatorin from Roots of Angelica dahurica. Adv. Mater. Res. 2012, 550-553, 1845-1851. [CrossRef] 
23. Živković, J.; Šavikin, K.; Janković, T.; Ćujić, N.; Menković, N. Optimization of ultrasound-assisted extraction of polyphenolic compounds from pomegranate peel using response surface methodology. Sep. Purif. Technol. 2018, 194, 40-47. [CrossRef]

24. Kazemi, M.; Karim, R.; Mirhosseini, H.; Hamid, A.A. Optimization of pulsed ultrasound-assisted technique for extraction of phenolics from pomegranate peel of Malas variety: Punicalagin and hydroxybenzoic acids. Food Chem. 2016, 206, 156-166. [CrossRef]

25. Musa, K.H.; Abdullah, A.; Al-Haiqi, A. Determination of DPPH free radical scavenging activity: Application of artificial neural networks. Food Chem. 2016, 194, 705-711. [CrossRef]

26. Bishnoi, A.; Chawla, H.M.; Pant, N.; Mrig, S.; Kumar, S. Evaluation of the radical scavenging activity of resorcinarenes by DPPH• free radical assay. J. Chem. Res. 2010, 34, 440-444. [CrossRef]

27. Shi, H.; Yang, H.; Zhang, X.; Yu, L. Identification and Quantification of Phytochemical Composition and Anti-inflammatory and Radical Scavenging Properties of Methanolic Extracts of Chinese Propolis. J. Agric. Food Chem. 2012, 60, 12403-12410. [CrossRef]

28. Xu, Z.; Cai, Y.; Ma, Q.; Zhao, Z.; Yang, D.; Xu, X. Optimization of Extraction of Bioactive Compounds from Baphicacanthus cusia Leaves by Hydrophobic Deep Eutectic Solvents. Molecules 2021, 26, 1729. [CrossRef]

29. Duan, H.; Zhai, K.F.; Cao, W.G.; Gao, G.Z.; Shan, L.L.; Zhao, L. The Optimum Extraction Process for Radix glycyrrhizae and Angelica dahurica (Fisch.) Benth.et Hook with Orthogonal Design. Indian J. Pharm. Educ. Res. 2017, 51, S631-S636. [CrossRef]

30. Feng, X.-F.; Jing, N.; Li, Z.-G.; Wei, D.; Lee, M.-R. Ultrasound-Microwave Hybrid-Assisted Extraction Coupled to Headspace Solid-Phase Microextraction for Fast Analysis of Essential Oil in Dry Traditional Chinese Medicine by GC-MS. Chromatographia 2014, 77, 619-628. [CrossRef]

31. Calderón-Oliver, M.; Ponce-Alquicira, E. Environmentally Friendly Techniques and Their Comparison in the Extraction of Natural Antioxidants from Green Tea, Rosemary, Clove, and Oregano. Molecules 2021, 26, 1869. [CrossRef] [PubMed]

32. He, X.; Yang, J.; Huang, Y.; Zhang, Y.; Wan, H.; Li, C. Green and Efficient Ultrasonic-Assisted Extraction of Bioactive Components from Salvia miltiorrhiza by Natural Deep Eutectic Solvents. Molecules 2019, 25, 140. [CrossRef] [PubMed]

33. Oomen, W.W.; Begines, P.; Mustafa, N.R.; Wilson, E.G.; Verpoorte, R.; Choi, Y.H. Natural Deep Eutectic Solvent Extraction of Flavonoids of Scutellaria baicalensis as a Replacement for Conventional Organic Solvents. Molecules 2020, 25, 617. [CrossRef] [PubMed] 